\title{
Estrategias de institucionalización del islam en contextos migratorios: el caso de Baitul Muqarram $^{1}$
}

\author{
Óscar Salguero Montaño \\ Universidad Complutense de Madrid \\ oscarsal@ucm.es
}

Resumen: En una sociedad aconfesional y plural los grupos religiosos comprenden el acceso al espacio público y la participación como derechos de ciudadanía, legitimando ante la sociedad $y$ las instituciones su estatus como actores sociales, diversos $y$ de pleno derecho en la vida pública, y respondiendo, en aras de su reconocimiento e inclusión, a otras demandas sociales. A partir del caso de la comunidad musulmana de Madrid Baitul Muqarram, este texto analiza las prácticas y los discursos desplegados en el escenario público, estableciendo una clasificación de las estrategias desarrolladas para la consecución de sus objetivos de institucionalización.

Palabras clave: pluralismo religioso, islam, islam bangladesí, espacio público, participación ciudadana, derechos de ciudadanía.

\footnotetext{
1 Este texto ha sido elaborado en el marco del proyecto CSO2015-66198-P «Expresiones Religiosas en el Espacio Urbano en Madrid y Barcelona (EREU-MyB)», Dirección General de Investigación Científica y Técnica y Subdirección General de Proyectos de Investigación del Ministerio de Economía y Competitividad, I+D+i Excelencia, convocatoria 2015.
} 
Strategies for the institutionalisation of Islam in migratory contexts: the case of Baitul Muqarram

Abstract: In a secular and plural society, religious groups understand participation
and access to public spaces as a citizenship right. This right legitimizes their status
as diverse social actors in public life with full legal rights, and meets various social
demands through its pursuit of recognition and inclusion for these groups. This
article examines the case of the Baitul Mugarram Muslim community in Madrid
and analyses its different practices and discourses in the public sphere, establishing a
classification of the strategies that they have developed to achieve their objectives of
institutionalization.

Keywords: religious pluralism, Islam, Bangladeshi Islam, public spaces, citizen engagement, citizenship rights. 


\section{Introducción}

Las migraciones procedentes de distintos países de tradición musulmana han constituido un importante factor para la institucionalización del islam actual en el Estado español, como en el caso de Madrid, donde su gestación estaría protagonizada al comienzo de los setenta por musulmanes que habían llegado años atrás desde Oriente Medio a España. Dos décadas después, la globalización económica, favorecedora de la movilidad y flexibilidad de los factores de producción, entre los que se incluye la mano de obra, y la exportación de la ideología consumista con productos y formas de vida destinadas a ser consumidas por poblaciones internacionales, diversificaría los perfiles nacionales, étnicos y socioeconómicos de los hombres y mujeres musulmanes que irían asentándose en el país, quienes, como algunos de sus predecesores, también contaban entre sus expectativas migratorias con la organización comunitaria en torno al hecho religioso, creando incipientes comunidades y abriendo los primeros oratorios y mezquitas de la época contemporánea.

Conforme el proceso de institucionalización de cada comunidad religiosa evolucionaba a partir de sus propias particularidades, y determinado por factores más generales como las políticas migratorias o el mercado laboral, irían cambiando también sus necesidades y demandas, en un primer momento relacionadas la mayoría de veces con la primigenia etapa de gestación e implantación de las comunidades, como la apertura de un lugar de culto. Desde los últimos años, en cambio, puede observarse cómo las principales reivindicaciones de las comunidades religiosas inmigradas ya consolidadas, especialmente entre confesiones minoritarias de gran implantación como el islam, se enmarcan en los derechos de ciudadanía, como son el acceso y visibilización en el espacio público, y la participación activa en la vida política local, en cuanto comunidad religiosa y, en su caso, también como comunidad étnica (Salguero, 2014: 417-418).

Por ello, desde que el fenómeno del pluralismo religioso cuenta ya con la suficiente trayectoria, las minorías religiosas comprenden el espacio público como un escenario en el que desplegar sus estrategias de visibilización y repertorios de movilización, escenario cada vez más frecuentemente elegido por los fieles de diversas confesiones, no solo la católica, para la celebración de actividades de distinto tipo (Salguero, 2018: 119): cultuales, casos de la procesión Hare Krisna del Ratha Yatra o la de los cristianos ortodoxos durante la noche de Pascua por los alrededores del templo cirio en mano (Fundación Pluralismo y Convivencia, 2018: 30, 26); proselitistas, como los expositores móviles de los testigos de Jehová en puntos de especial trasiego urbano o las prédicas evangélicas de On The Red Box; sociales y políticos, casos de los pronunciamientos públicos, en ocasio- 
nes interreligiosos, contra la violencia, o las manifestaciones católicas «antigénero» (Blázquez-Rodríguez, Cornejo y Pichardo, 2018), y culturales, como las clases de lengua materna o las jornadas de puertas abiertas en los lugares de culto. Esta visibilidad pública de las minorías religiosas no solo se cartografía sobre el espacio (Salguero, 2014: 20), es observable también en la vida pública, especialmente en la local, en donde con cada vez más frecuencia asistimos a la presencia de grupos y representantes religiosos en foros y plataformas ciudadanas gestadas en torno a temas seculares como la defensa de los derechos humanos, junto con otras confesiones y/o asociaciones civiles de distinto tipo; o a la concurrencia de estos grupos a programas de ayudas sociales y concesiones públicas, en ámbitos como la asistencia a personas migrantes, correligionarias o no, como avalan actualmente los proyectos de varias ONG confesionales centrados en la acogida de personas solicitantes de protección internacional, casos de la católica La Merced Migraciones y la evangélica Diaconía.

Unas nuevas necesidades y demandas que traen consigo una serie de prácticas y discursos que reescriben el contexto migratorio en el que se insertan los grupos religiosos de las confesiones minoritarias. Con la consolidación y arraigo de algunos de los colectivos migrantes, progresivamente han venido consolidándose también algunas de las comunidades religiosas gestadas en su seno, por lo que las aspiraciones colectivas ya no se relacionan con las vicisitudes de «la llegada» en aras de cierto afán integrador en un marco multicultural, sino más bien con demandas de ciudadanía y reivindicación de derechos, que exigen el reconocimiento y dignificación de las singularidades identitarias, y pretenden ir más allá de la integración en el contexto ajeno de la sociedad receptora, apostando por su plena «inclusión» en un contexto intercultural construido entre los colectivos migrantes y la sociedad en general y al que ambas partes tendrán que adaptarse.

\section{Migraciones, institucionalización religiosa y ciudadanía}

Si bien el pluralismo religioso, y más especialmente el caso del islam, no es un fenómeno ex novo en el Estado español, las migraciones procedentes de países de tradición musulmana han constituido un importante factor para la configuración del actual islam español. Mientras que en otros territorios como Andalucía el movimiento de conversos tuvo un papel destacado (Tarrés y Salguero, 2010: 299), en el caso de Madrid, el proceso de gestación del islam institucionalizado contemporáneo sería protagonizado a comienzos de los años setenta por un colectivo de musulmanes procedentes de países como Palestina, Jordania, Egipto, 
Siria y Líbano, llegados a la capital desde mediados del siglo pasado, primero por motivos académicos, y posteriormente por otras circunstancias derivadas de los conflictos de Oriente Próximo (Algora, 2011: 216). En el seno de este colectivo se gestaría la Asociación Musulmana de España (AME), constituida como entidad religiosa el 23 de abril de 1971. Desde entonces la impronta migratoria sobre el mapa del islam madrileño, en consonancia con el panorama estatal, ha venido siendo una constante. Según el informe demográfico editado anualmente por la Unión de Comunidades Islámicas de España (UCIDE), Madrid es, a 31 de diciembre de 2018, después de Cataluña (533.600) y Andalucía (324.680), la tercera comunidad autónoma en número de personas musulmanas censadas ${ }^{2}$, estimadas según la federación islámica en 290.991 (un 14,60\% de la población total), cinco mil más que en el año anterior ${ }^{3}$. La nacionalidad española es la mayoritaria, con un total de 176.832 , seguida de la marroquí, con 76.549 , la cual se mantiene más o menos estancada ${ }^{4}$ en comparación con otras nacionalidades como la bangladesí, que, pese a tratarse de un colectivo poco numeroso, lleva desde los últimos años experimentado un crecimiento progresivo ${ }^{5}$ (Observatorio Andalusí, 2018: 7-9).

No parece, por tanto, que finalmente los procesos de secularización de la sociedad industrial acabaran por insertar a los migrantes en la tendencia «moderna» de creciente irrelevancia de la dimensión religiosa en la vida social y personal. Por el contrario, las instituciones religiosas han fortalecido al colectivo migrante de diversas maneras, con recursos materiales (asistenciales y de sustento), y también sociales, haciendo de catalizadores y no raramente de promotores, de redes de relaciones basadas sobre la doble pertenencia confesional y étnica, facilitando «la reconstrucción de la identidad cultural y su inclusión en el nuevo contexto» (Ambrosini, 2008: 13). Desde una perspectiva global, puede afirmarse que los movimientos religiosos de hoy, además, poseen una capacidad singular para señalar las anomalías de la sociedad (Kepel, 1995: 18), en cuanto actores que conciben el fenómeno religioso también como repertorio para el cambio social; un fenómeno que en la posmodernidad es heterogéneo, múltiple y a veces contradictorio, en el que se entrelazan creencias religiosas y movimientos de oprimidos

\footnotetext{
2 Sin embargo, si cruzamos estas estimaciones con las cifras del Padrón Municipal, puede observarse cómo mientras la estimación del número de personas musulmanas en la Comunidad de Madrid supone el 4,42\% de su población total, las ciudades autónomas de Melilla y Ceuta ostentan los porcentajes más altos de todo el Estado, con 44.977 (52,06\%) y 37.002 (43,46\%), respectivamente, seguidas de la Región de Murcia, con 105.326 $(7,12 \%)$.

3278.976 (2015), 283.063 (2016), 285.993 (2017) у 290.991 (2018).

477.116 (2015), 76.759 (2016), 75.766 (2017) y 76.549 (2018).

54.622 (2015), 4.878 (2016) 5.358 (2017) y 6.116 (2018).
} 
(Gramsci, 1971:328), en este caso encarnado en la comunidad inmigrada de creyentes. Es decir, las instituciones religiosas inmigradas actúan como componentes activos en el mantenimiento y desarrollo de las identidades colectivas y las referencias religiosas de los colectivos que albergan. El devenir de las mismas está sujeto a factores generales de carácter estructural, como el propio aumento de la inmigración musulmana, así como el modo de entender la gestión de la diversidad religiosa por las Administraciones públicas, la sociedad y los propios actores religiosos; junto con una serie de dinámicas más específicas e interrelacionadas como el aumento de la islamofobia y de los discursos políticos y sociales excluyentes o la radicalización de algunos sectores (Planet, 2018: 1-22). En este sentido, la institucionalización de las comunidades religiosas inmigradas es concebida como un proceso que arranca con la propia gestación de la comunidad, de modo que mayores niveles de institucionalización se corresponderán generalmente con un mayor grado de interactuación con el heterogéneo contexto al que pertenecen, que es donde, en definitiva, plantean sus principales necesidades y demandas $y$, donde, en su caso, pueden emerger los potenciales conflictos.

En el caso del islam español, con la progresiva consolidación de los colectivos migrantes (junto con la salida a escena de las denominadas «segundas generaciones») y la transformación de las comunidades de fieles — de «islam inmigrado» a «islam español»- irán generándose otras necesidades y demandas, que, a su vez, serán también medios desde donde se realizarán nuevas y ulteriores reivindicaciones. Las demandas de visibilización y participación activa en la vida pública han venido desplazando la que fue la principal necesidad de las comunidades que iban surgiendo al hilo de los flujos migratorios, la apertura de oratorios (Moreras, 1990: 64). En un primer momento durante la década pasada se fue inscribiendo en el Registro de Entidades Religiosas un número cada vez mayor de oratorios y mezquitas para atender las necesidades de un colectivo mayoritariamente migrante (y marroquí) e integrado por familias que comenzaban a demandar una serie de servicios (educativos, sanitarios y religiosos). Con la llegada de la actual década, sin embargo, el ritmo de inscripciones musulmanas ha venido decreciendo significativamente (Salguero, 2018: 120), a la vez que diversificándose extraordinariamente el origen de la población musulmana asentada.

Las nuevas pretensiones de visibilización y participación pública, en cuanto signos de legitimación social y reconocimiento institucional, han dado comienzo a una nueva etapa en el proceso de institucionalización de las comunidades musulmanas. La participación en «lo público», contar entre los recursos del capital social propio con un mínimo de popularidad en el municipio, es uno de los indicadores del grado de consolidación comunitaria que contribuyen a llegar a 
ser un «actor social» con capacidad para incidir sobre el medio. Este reconocimiento suele ser fruto de la participación de las comunidades en la vida pública del municipio a través de las obras sociales y de otras actividades que puedan ser consideradas de cierto interés o utilidad pública (Salguero, 2014:417). Entre las confesiones minoritarias pueden distinguirse diversas estrategias de participación dependiendo del ámbito de interlocución. Por un lado, se encuentran las estrategias de participación en el ámbito gubernativo público, que persiguen el establecimiento de relaciones de interlocución más o menos fluidas con las Administraciones públicas relacionadas directa o indirectamente con la gestión pública de la diversidad religiosa, tales como la Subdirección General de Relaciones con las Confesiones del Ministerio de Justicia o la Fundación Pluralismo y Convivencia, y más especialmente con el Ayuntamiento correspondiente, a través de la inclusión en foros y plataformas ciudadanas, la concurrencia a programas sociales y el establecimiento de canales de comunicación. Por otro lado, cada vez es más usual la participación de comunidades religiosas en los ámbitos asociativos y vecinales, que incluyen relaciones tanto con otras comunidades religiosas de la misma u otra confesión (a modo de jornadas interreligiosas, actos conmemorativos, etc.), como con otras organizaciones no religiosas, especialmente asociaciones culturales y sociales, como ONG, asociaciones y movimientos vecinales, etc.

La visibilidad, junto con la participación, forma parte de este doble proceso de legitimación y reconocimiento en el contexto urbano en el que se insertan los grupos religiosos, el cual puede cartografiarse sobre el territorio a través de las celebraciones religiosas, conmemoraciones y otros actos confesionales no cultuales realizados en la calle y en los equipamientos comunitarios públicos (Salguero, 2014: 418). La visibilidad en el espacio público también cuenta con una serie de distintas estrategias. Una, la de rituales religiosos a través de la celebración de festividades multitudinarias, caso de los dos rezos islámicos colectivos más importantes del calendario hegiriano, el Eid al-Fitr y el Eid al-Adha. Otra, la del amplio abanico de prácticas proselitistas en plena calle, si bien, para el caso del islam estas prácticas son poco frecuentes, exceptuando casos particulares como la carpa «informativa» que la Fundación Alulbeyt España, chiita duodecimana, instaló en las céntricas plazas madrileñas de Sol en 2016 y de Moncloa en 2018, durante el mes de Muharram, después de la Ashura, en conmemoración del martirio del imam Husain. Y otra más que se corresponde con un no menos amplio conjunto de actos seculares, que van desde el reconocimiento de la diversidad cultural y/o étnica (actividades generalmente culturales en las que se ponen en valor elementos identitarios de las comunidades de origen, como la lengua y las tradiciones culturales) hasta la adhesión a repertorios sociales más generales, 
caso de las cada vez más frecuentes muestras públicas de rechazo de la violencia autodenominada yihadista o de citas diversas de carácter interreligioso. Aquí es preciso puntualizar que si bien la ocupación del espacio público por las comunidades musulmanas sigue obedeciendo en muchos casos a la falta de espacio físico para albergar a grupos más o menos multitudinarios (Salguero, 2010: 485) y, en general, a una "precariedad endémica de recursos» (Alonso et alii, 2010: 171), la visibilización comunitaria a través de diversos actos en el espacio público, así como la participación activa en la vida pública, también responden en ocasiones cada vez más frecuentes a dos valores complementarios entre sí: la reivindicación de la diferencia y el derecho a la inclusión (Salguero, 2018: 120).

El énfasis en la diversidad se caracteriza por la reivindicación de lo distintivo y la búsqueda de una voz propia en la sociedad general, en la línea de la «ciudadanía religiosa» de Hudson (2003), según la cual los marcos normativos y la propia institución de la ciudadanía necesitarán ser reconstituidos de acuerdo con los principios pluriconfesionales, además de seculares. A veces, esta estrategia consiste en el uso del espacio público para actividades confesionales como rituales y rezos colectivos; otras veces se expresa potenciando elementos distintivos (étnicos, nacionales, confesionales, denominacionales...) en la búsqueda del reconocimiento social de sus particularidades. Estos «rituales en la diáspora» de las comunidades musulmanas ponen en cuestión las teorías de la modernización más convencionales, que sugerían que la influencia secularizadora de la sociedad occidental llevaría a un progresivo abandono de estas ritualidades, mientras que el resultado ha sido que se trata de manifestaciones colectivas que las primeras generaciones de musulmanes han mantenido como recuerdo y refuerzo del vínculo con su país de origen, y que además son secundadas por las siguientes generaciones (Alonso et alii, 2010: 175).

El énfasis inclusivo, por su parte, emplea recursos, demandas y representaciones socialmente hegemónicas que escenifican la asunción por los grupos religiosos de los valores y preocupaciones compartidos por la sociedad en su conjunto, facilitando el enmarcado para sus eventos que aluden a la alineación entre las confesiones y la sociedad de la que forman parte. Otras veces, el valor de la inclusión se materializará en una mayor o menor invisibilización de la dimensión religiosa, en forma del «secularismo estratégico» (Vaggione, 2005), concretado en el desplazamiento de las argumentaciones religiosas como adaptación estratégica a nivel de las narrativas y las discursividades articuladas para defender determinadas concepciones generalmente más tradicionales.

Desde esta óptica, las manifestaciones de las comunidades musulmanas en el espacio y vida públicas pueden concebirse como una de las estrategias elegidas 
para «establecer una conexión relacional con esta sociedad, expresando una singularidad propia y, al mismo tiempo, su voluntad de formar parte de ella» (Alonso et alii, 2010: 176). La pretensión de visibilización se sustenta institucionalmente sobre la base del derecho fundamental a la libertad religiosa y de culto, que contempla el artículo 16.3 de la Constitución, junto con la libertad ideológica; apartado que reconoce igualmente la participación pública de las confesiones religiosas traducidas en «relaciones de cooperación con la Iglesia católica y las demás confesiones». Para la materialización de ello, además, las confesiones religiosas en el actual «mercado religioso» plural (Berger, 1967; Luckman, 1967) entablarán con mayor o menor éxito una serie de procesos de participación que requieren en ocasiones una negociación por la presencialidad y uso del espacio con distintos actores: las otras confesiones, la vecindad y los habitantes de la ciudad — muchos de ellos fieles en potencia- y muy especialmente con los actores detentadores de la propiedad y la gestión del espacio urbano: los poderes públicos y los entes privados (Salguero, 2018:121).

La ciudadanía, que apunta a la definición de la identidad de los individuos en el espacio público (Thiebaut, 1998: 24), incluida la de los creyentes, engloba una serie de derechos que van de la pertenencia plena a una comunidad política como miembros de la misma y respetados en su singularidad hasta su participación activa en la misma. Lo público se convierte así para las comunidades de fieles, especialmente las inmigradas, en un «espacio de representación de lo imaginario y lo simbólico dentro de una existencia material» (Lefebvre, 2013: 16), un espacio político para el ejercicio de los derechos cívicos y un «espacio para la alteridad» (Alguacil, 2008: 204), donde «se construyen la expresión e identificación social de los diversos» (Carrión, 2007: 84).

A partir de lo expuesto, el presente texto plantea la hipótesis según la cual en el contexto de una sociedad aconfesional y plural los grupos religiosos comprenden el acceso al espacio público y la participación en la vida pública local como reivindicaciones integradas en los derechos de ciudadanía, legitimando ante la sociedad y las instituciones su estatus como actores sociales, diversos y sujetos de pleno derecho en la vida pública, a la vez que respondiendo, en aras de su reconocimiento social e institucional, a otros tipos de demandas sociales vinculadas a valores como la modernidad y la transparencia. Para dar respuesta a este interrogante, este texto analiza las circunstancias en las que los grupos religiosos plantean estas reivindicaciones, y describe las prácticas y discursos que se despliegan en la palestra de «lo público». Para ello, se analizará el caso de la comunidad musulmana de Madrid Baitul Muqarram, y la serie actividades más significativas que se desarrollaron entre abril de 2017 y febrero de 2019, estableciendo una 
clasificación de las estrategias desplegadas para la consecución de sus objetivos de institucionalización, que pasan por la visibilización y la participación comunitaria en la esfera pública local.

\section{Cuestiones metodológicasł etnografía de barrio y dimensión ritual}

Este estudio parte del acervo de haber estado inserto en una investigación de mayores dimensiones, con la pretensión principal de explorar, describir y analizar la dimensión más visible de las comunidades religiosas contemporáneas: la organización de actividades, eventos, manifestaciones y celebraciones en el espacio público. Ha sido desarrollada por un total de 41 investigadoras e investigadores en las ciudades de Barcelona y Madrid e integrada por diversos casos correspondientes a distintas confesiones: cristianos católicos y protestantes de distintas tradiciones, sikhs, musulmanes sunníes y chiíes, y otras espiritualidades. Prevista para un tiempo inicial de tres años, entre 2015 y 2018; ha sido prorrogada por un año más, correspondiéndose algunos de los datos etnográficos y resultados que aquí se presentan con este período de ampliación, aportando nuevos elementos a un primer acercamiento del caso de la comunidad musulmana bangladesí del barrio madrileño de Lavapiés (Salguero, 2018).

El sujeto de estudio, conformado por una población creciente que roza los tres millares de personas que en su mayoría mantienen lazos transnacionales con su país de origen, va ostentando progresivamente cada vez mayor visibilidad pública, y las ramificaciones del mismo hacia otros ámbitos más allá del religioso, como el empresarial, el político o el asociativo, contribuyen decisivamente a ello. En este marco, es comprensible el importante espacio destinado al trabajo etnográfico desarrollado entre abril de 2017 y febrero de 2019, para atender a una continuada presencia en la esfera pública con diferentes actividades, lo que ha hecho que las técnicas de observación hayan desempeñado un relevante papel, tal y como se extrae del cuaderno de campo, que registra un total de once actos públicos formales: la Jornada de puertas abiertas en la mezquita Baitul Muqarram (13 de abril de 2017), un acto público en la plaza de Lavapiés de reconocimiento del distrito Centro «libre de islamofobia» (30 de mayo de 2017), los rezos colectivos del Eid al-Fitr (25 de junio de 2017) y del Eid al-Adha (1 de septiembre de 2017) en las canchas deportivas municipales del Casino de la Reina, la concentración en la plaza de Lavapiés de la comunidad musulmana bangladesí contra los atentados de Barcelona y Cambrils (22 de septiembre de 2017), la visita de la alcaldesa Manuela Carmena y el concejal del distrito Centro, García Castaño, a la 
mezquita Baitul Muqarram (28 de mayo de 2018), nuevamente el Eid al-Fitr (15 de junio de 2018) y el Eid al-Adha (21 de agosto de 2018) también en el Casino de la Reina, la II Jornada de puertas abiertas en la mezquita (17 de noviembre de 2018), la participación como anfitriona de la mezquita en el programa «Conoce la diversidad religiosa de Madrid» de la Fundación La Merced Migraciones (28 de noviembre de 2018) y la conmemoración en la plaza de Lavapiés de los sucesos de la Universidad de Dacca en 1951 por la defensa de la lengua bengalí (21 de febrero de 2019). La observación en unas y otras ha basculado entre la directa, limitada a la observación misma y el registro de los datos cuando las circunstancias así lo determinaron, a la más participante en aquellos actos de interacción entre organizadores y asistentes, como las distintas visitas a la mezquita.

También se realizó una serie de entrevistas con informantes clave, seleccionados entre distintos actores: religiosos, de la propia comunidad, de otras comunidades vecinas musulmanas y también de otras confesiones; públicos, que han incluido a la concejalía del distrito y una técnica municipal, y asociativos, con el personal de una organización que trabaja con la comunidad bangladesí. Otras entrevistas realizadas fueron las de carácter informal que iban surgiendo entre el vecindario y los comerciantes o con el personal público participante en algunas de las actividades, como policías, sanitarios y miembros de protección civil (Salguero, 2018: 123).

Al tratarse de un contexto multicultural y plurirreligioso, estas técnicas del trabajo de campo se han desarrollado simultáneamente y con carácter complementario con otros grupos religiosos, casos de otras mezquitas como Al-Huda, en la castiza calle del Oso y de membresía mayoritariamente marroquí; y también con otras confesiones vecinas, como el catolicismo, que cuenta en el barrio con tres históricas parroquias (San Lorenzo, de San Salvador y San Nicolás y de San Millán y San Cayetano), o las cinco denominaciones evangélicas, entre las que se encuentra una de las iglesias de Filadelfia más importantes de la ciudad y con membresía gitana en su práctica totalidad.

En la base de la investigación además se ha empleado una serie de fuentes de carácter documental, técnico y jurídico: documentos internos administrativos de la propia comunidad; fuentes estadísticas oficiales, como el Padrón Municipal, y algunas otras de organismos relacionados, como el Registro de Entidades Religiosas del Ministerio de Justicia o el Observatorio del Pluralismo Religioso en España, así como de las propias confesiones, como los informes anuales del Observatorio Andalusí entre 2015 y 2018; prensa online actual y de archivo, que ha permitido contrastar algunos de los hechos pasados narrados durante las entrevistas y acercarse a los discursos institucionales de actores relevantes como el 
Ayuntamiento; legislación y normativa administrativa afecta, en sus niveles estatal, autonómico y local, y una serie de programas y planes de organismos públicos relacionados, como el Plan de Derechos Humanos (2017-2020) del Gobierno local o la campaña «Tacha el odio» de la Unidad de Gestión de la Diversidad de la Policía Municipal de Madrid.

El análisis de estas actividades públicas ha descansado en gran medida sobre el enfoque de la «dimensión ritual» de la antropología de la religión (Leach, 1976), que permite la apreciación de la perspectiva ritualista en un variado conjunto de dispares acciones comunicativas (Falk Moore y Myerhoff, 1977; Bell, 1992; Bromberger, 1995) y la atención a nuevas formas de visibilización de las confesiones religiosas, como la «eventización»(Pfadenhauer, 2010). Fruto de ello, adaptativamente se iría ampliando el campo, incorporando al estudio de los rituales estrictamente religiosos - como el salat de los viernes o los dos grandes rezos colectivos del año- el de otras manifestaciones públicas que, pese a su condición no religiosa, se configuran como rituales seculares, cuya misión es, en última instancia, «decir algo sobre los individuos que participan», manifestando, desde un punto de vista socialmente situado, el estatus del individuo en su sociedad (Leach, 1976:35).

Los resultados del trabajo de campo han descansado sobre la sinergia de los acercamientos desde tres posiciones distintas y complementarias: la del propio sujeto investigador enmarcado en la figura del antropólogo (técnico) cuya actividad está promovida por una institución académica que aporta legitimidad institucional en la entrada en el campo; la del vecino que aporta confianza y cercanía, permitiendo aproximaciones más informales y el acceso a cuestiones más profundas relacionadas en su mayoría con discursos y prácticas sobre las especificidades del barrio (Salguero, 2018: 124), y la de agente de cambio, pues durante la realización de la prorrogada fase del trabajo de campo la investigación fue compatibilizada con la coordinación de un proyecto de prevención de la islamofobia, en el cual participaría de forma activa la comunidad bangladesí protagonista del estudio de caso $^{6}$. Estos tres abordajes, además de acomodar la figura del investigador en el campo, se han retroalimentado entre sí, facilitando la adaptabilidad de la investigación a las sucesivas circunstancias que han ido surgiendo durante el trabajo de campo y abriendo otros canales con potencial investigador.

6 Proyecto «Salam: Promoción de la convivencia intercultural e interreligiosa y prevención de la intolerancia por motivos religiosos», promovido por la Fundación La Merced Migraciones y financiado por el Ministerio de Trabajo, Migraciones y Seguridad Social y el Fondo de Asilo, Migración e Integración de la Unión Europea, convocatoria de julio de 2017. 


\section{De «islam inmigrado» a «islam de barrio»ः el caso de Baitul Muqarram}

La comunidad musulmana de Madrid Baitul Muqarram se gestó a comienzos de la década pasada entre un grupo de fieles musulmanes procedentes de Bangladés, y residentes en el céntrico barrio de Embajadores, popularmente conocido como Lavapiés. El elemento migratorio es, por tanto, consustancial a Baitul Muqarram, concebida como una «comunidad religiosa inmigrada», cuyo mismo nombre evoca a la mezquita más importante del país asiático, situada en la capital del país, Dacca.

A 1 de enero de 2019 constaban censadas en el Padrón Municipal de Habitantes de la ciudad de Madrid un total de 6.288 personas procedentes de Bangladés (658 más que el pasado año). 2.935 de las cuales residen en el distrito Centro y casi su práctica totalidad en el barrio de Lavapiés, quienes constituyen la segunda nacionalidad más numerosa del distrito, después de la italiana, representando al 24,65\% del total de personas extranjeras del distrito Centro, 11.908 entre un total de 45.433 vecinos y vecinas. Se trata de un grupo heterogéneo, en el que conviven diversas provincias de procedencia y distintas etnias y dialectos (Camacho, 2013: 5-6), y conformado mayoritariamente por hombres jóvenes o agrupados en familias jóvenes con hijos pequeños (Salguero, 2018: 125), tal y como delata el bullicio matutino en la puerta del colegio de San Alfonso.

En general, y de forma parecida al caso en otras grandes ciudades como Londres (Eade y Garbin, 2002: 139), se trata de un colectivo precarizado, empleado por cuenta ajena en comercios (fruterías, tiendas de alimentación y de artículos electrónicos) y en negocios de restauración anunciados como «indios»o «hindúes», y también en actividades de economía sumergida como la de los «lateros» (Salguero, 2018: 127). La mayoría de las mujeres, por su parte, trabajan en sus casas al cuidado de sus familias. Unas y otros presentan en común otras dificultades como un escaso conocimiento de la lengua española, si bien tampoco parece obstáculo para la adecuada atención a la clientela de muchos de estos negocios, conformada cada vez más por una población flotante de turistas y visitantes de Airbnb, que encuentran en estos restaurantes una oferta culinaria tan económica como exótica, satisfaciendo así las expectativas depositadas en la visita al barrio más cool del mundo (según la revista internacional de ocio City Life Index en septiembre de 2018), en el que la multiculturalidad y la turistificación forman parte por igual de su imagen de marca, fraguada a golpes de especulación inmobiliaria y turistificación (Sequera, 2014: 237) y de un voraz proceso de gentrificación (Salguero, 2018: 128). 
La mayoría de los hombres y mujeres del colectivo bangladesí se adscribe confesionalmente al islam sunní, y es la mezquita del esquinado número 9 de la calle Provisiones el espacio habitual de sus prácticas religiosas y, en su caso, de interacción social fuera de los espacios y tiempos del trabajo ${ }^{7}$. Constituida como asociación cultural primero en 2003 con el curioso nombre de Centro Cultural Islámico Internacional España Madrid, y después en 2009, como entidad religiosa ante el Ministerio de Justicia, con el de Comunidad Musulmana de Madrid Baitul Muqarram, esta comunidad se gesta en el seno de otras experiencias asociativas de los migrantes bangladesíes de la zona, como la Asociación de Bangladés en España, inscrita como entidad cívica social, cuya presidencia es símbolo de prestigio social entre los connacionales. Junto con esta, se dan cita otras asociaciones bangladesíes de diferente tipo, como la Asociación de Mujeres Progresistas de Bangladés, afín a la Asociación de Bangladés en España, con la que comparte sede; la Bussines Association Banglades, que representa los intereses de la patronal bangladesí en España que se concentra en este barrio (Camacho, 2013: 9); o partidos políticos en la diáspora, como la Liga Awami, de centroizquierda y actualmente en el Gobierno; el Bangladesh Nacionalist Party, en la oposición, y cuyo presidente en España es a su vez el presidente de la mezquita; y el Jatiya Party, como alternativa conservadora a los dos grandes partidos citados. La más reciente de las asociaciones creadas es Valiente Bangla (Salguero, 2018: 125), en defensa, pese a su nombre, de los derechos de los migrantes de toda procedencia, en un barrio en el que persisten la marginalidad (Gómez, 2006: 3) y la infravivienda (Pérez, 2009), además de otros fenómenos como la «hiperpresencia policial» $y$ las «identificaciones preventivas» por criterios raciales (García-García, 2014: 8). En las filas de Valiente Bangla se encuentran fieles de alguna de las comunidades musulmanas del barrio, caso mismo de su presidente, miembro activo de Baitul Muqarram. Esta asociación, además, colabora puntualmente con la mezquita de Bangladés en la organización de algunas actividades, «hasta el punto de que las fronteras entre ellos son menos rígidas de lo que su discurso sugiere», tal y como afirman Eade y Garbin al hilo de los debates entre bangladesíes secularistas e islamistas en Londres (2006: 91). La doble «militancia» religiosa y

\footnotetext{
7 En el número 14 de la calle Caravaca abre sus puertas otra comunidad musulmana de fieles bangladesíes, la Hazrat Sahjalal Lotifia Cultural Center (Bangladés), la cual cuenta con bastante menos representatividad que Baitul Muqarram y una presencia casi invisible en la esfera pública local. Las relaciones entre ambas comunidades son escasas. Esta comunidad forma parte de la Bangladesh Anjumane-Al-Islah Spain, una organización no constituida formalmente en España y que responde a un movimiento internacional presente en aquellos lugares del mundo donde existen asentamientos bangladesíes significativos. Además de la sede madrileña, en Barcelona se encuentra el Centro Cultural Islámico Lotifia Fultoli Barcelona Spain, en el barrio de El Raval (Salguero, 2018: 126). El nombre de Hazrat Sahjalal conmemora la figura del sufí Hazrat Shah Jalal, integrado en el ejército musulmán de Sylhet, que propagaría el islam en el territorio de Bengala en la primera mitad del siglo XIV de nuestra era.
} 
social de algunos y algunas bangladesíes cuestiona la tendencia de asociar «a las personas musulmanas con una lucha estructurada casi únicamente alrededor de la reclamación de derechos identitarios basados en la musulmaneidad», cuando la realidad es que su «conciencia de subalternidad no solo se estructura alrededor de una identidad religiosa no aceptada, sino también, y, sobre todo, alrededor de una precariedad económica y laboral muy pertinaz en el caso de las poblaciones musulmanas» (Mijares y Lems, 2018: 126).

A partir de este contexto, puede comprenderse la significativa y creciente presencia del colectivo musulmán bangladesí en la esfera pública local. Una presencialidad que ha venido aumentando con el tiempo, parejo a la consolidación del colectivo migrante bangladesí, el cual abarca un amplio tejido humano e institucional, integrado por un importante número de personas procedentes de Bangladés y descendientes de estas que forman parte del paisaje cotidiano de Lavapiés y por una red de asociaciones en distintos ámbitos sociales, políticos y económicos, algunas de las cuales cuentan con cierta visibilidad entre los movimientos sociales de la ciudad y/ o participan en la vida pública local a través de diversos programas y proyectos sociales y culturales promovidos por entidades públicas y privadas.

En este contexto, Baitul Muqarram ha puesto en marcha desde los últimos años un proceso de institucionalización que abarca dos dinámicas generales y complementarias: una, la visibilización en el espacio público de repertorios tanto religiosos como culturales y étnicos, por ejemplo, celebrando dos veces al año la oración del Eid en las canchas municipales al aire libre o manifestándose contra los atentados autodenominados yihadistas; y otra, la participación en la vida pública del barrio y de la ciudad, abriendo su lugar de culto en varias ocasiones a vecindario e instituciones públicas y ONG, pero también realizando reivindicaciones y demandas de derechos de ciudadanía relacionadas con el reconocimiento institucional, así como otras ulteriores — caso de la pretendida apertura de un gran Centro Cultural Islámico en el distrito Centro- que ascienden al colectivo bangladesí a una etapa ya distante de la llegada, marcada por las imposiciones de la integración y orientada en lo religioso a la gestación de una primigenia comunidad religiosa, preocupada fundamentalmente por la apertura y mantenimiento del lugar de culto.

A continuación, se dará cuenta del conjunto de distintas estrategias desplegadas por Baitul Muqarram en un ámbito distinto al de las primeras necesidades, que se circunscribía al propiamente religioso (reconocimiento público e inscripción en el Registro de Entidades, reivindicaciones directamente relacionadas con el culto, como lugares y cementerios..+), y que abarca hoy el acceso con plenitud de derechos al espacio público y a la vida política local, como espacios para el re- 
conocimiento y la reivindicación de la diferencia. Para ello se analizará una serie de manifestaciones públicas de esta comunidad, así como su significado e implicaciones en términos de reivindicación de la diferencia y de derecho inclusión, lo que permitirá elaborar una clasificación de estrategias de institucionalización en contextos sociales migratorios similares.

\section{Espacio público y participación: hacia una clasificación de las estrategias de institucionalización de las comunidades musulmanes inmigradas}

Se ha registrado un mayor número de actos seculares que religiosos, partiendo de que en algunos de ellos lo secular y lo religioso han sido más bien una dimensión, realizándose acciones seculares con cierta religiosidad, y viceversa. Únicamente cuatro de los once actos observados (que han ocupado el grueso de las manifestaciones públicas de la comunidad en estos dos años) pueden comprenderse como estrictamente religiosos: los dos grandes rezos colectivos de los años 2017 y 2018. El resto son eventos seculares, más o menos ritualizados. Este secularismo estratégico (Vaggione, 2005) corrobora el citado cuestionamiento de la tendencia de asociar «a las personas musulmanas con una lucha estructurada casi únicamente alrededor de la reclamación de derechos identitarios basados en la musulmaneidad» (Mijares y Lems, 2018: 126). Es en este marco, por tanto, desde el que ha de comprenderse la siguiente clasificación de estrategias de institucionalización.

La visibilidad y participación en el espacio público de los grupos religiosos puede alcanzarse a través de distintas estrategias, entre las que destacan la realización de prácticas del proselitismo, la celebración de rituales religiosos y la organización y/o participación en actos seculares. La primera de ellas, el proselitismo, no se encuentra entre el conjunto de estrategias de la comunidad de Baitul Muqarram, ni de las comunidades musulmanas en general, no al menos en una dimensión pública ${ }^{8}$; cuestión distinta sería la de algunas prácticas identificadas con la dawa y llevadas a cabo en contextos de cierta privacidad entre individuos y supuestamente sin coacción alguna?

La celebración de rituales religiosos, por su parte, sí ha tenido un protagonismo destacado en este estudio de caso. Los rezos del Eid al-Fitr y el Eid al-Adha en las canchas deportivas al aire libre de las instalaciones municipales del Casino de la Reina, que albergan a unos seis millares de personas, convierten a la impro-

8 Y si tu Señor quisiera creerían todos los que están en la tierra. ¿Acaso puedes tú obligar a los hombres a que sean creyentes? Ningún alma puede creer si no es con permiso de Alá (Corán, 10: 99-100).

Llama al camino de tu Señor con sabiduría y buena exhortación. Discute con ellos de la manera más conveniente (Corán, 16: 125). 
visada musala en un espacio de proximidad (a escasa distancia de la mezquita), accesible y de legítimo uso; y también en un espacio central, al tratarse de punto referencial del islam local por la proximidad con el resto de mezquitas, por el uso cotidiano de jóvenes musulmanes que practican algún deporte o simplemente «paran» ahí, y con carácter anual también por ser uno de los escenarios del festival de «Las noches de Ramadán» (Salguero, 2018: 133). Otros rituales religiosos son celebrados en un espacio que podría denominarse como «temporalmente público», caso de la celebración anual de un iftar durante el mes de Ramadán al que son invitados representantes y gestores municipales y el vecindario en general. Partiendo de que la mezquita permanece abierta al público la mayor parte del día, ordinariamente solo acuden creyentes, y en días como este lo hacen también no creyentes. Las personas invitadas participan activamente en el acto. Las mujeres no van todas veladas, pero sí su mayoría, creyentes o no. Todos comen y beben con los anfitriones y confraternizan con ellos, quienes aprovechan también para relacionar algunos aspectos básicos del islam con la total oposición a cuestiones como la violencia, además de plantear demandas como la pertinencia de contar en el distrito Centro con un gran centro cultural islámico al modo de las mezquitas de la M30 y Estrecho.

El reconocimiento de la diferencia está manifiestamente presente en los grandes rituales religiosos colectivos, e igualmente en el iftar aunque con menor impronta visual en el paisaje urbano. En todos se potencian en diferente grado elementos etnorreligiosos en la búsqueda del reconocimiento social de sus particularidades. Son sus creencias y prácticas religiosas, y también sus costumbres, las que se muestran públicamente, de manera que hasta el propio menú del iftar aporta información cultural sobre el grupo étnico y nacional. Pero el énfasis inclusivo está no menos presente: desmontar durante el ambiente relajado del encuentro y la comida el interesado binomio islam-violencia significa la alineación entre la comunidad y la sociedad, en términos de modernidad y transparencia; transparencia no solo semántica, también performativa en los rezos colectivos al aire libre, a la vista de todosः «Estamos rezando, no tenemos nada que ocultar».

La tercera de las estrategias de visibilización en el espacio público es celebración en él de actos seculares, casos del reconocimiento público del distrito Centro «libre de islamofobia» en mayo de 2017, la concentración contra los atentados de Barcelona y Cambrills en septiembre de 2017 y la conmemoración de los sucesos de la Universidad de Dacca en 1951 por la defensa de la lengua bengalí en febrero de 2019. Estas tres apariciones en el espacio público se realizaron en la plaza de Lavapiés, un espacio también central en cuanto punto neurálgico de la vida comunitaria (Salguero, 2018: 122). Los tres se han tratado de actos más mino- 
ritarios que las grandes puestas en escena del Eid, lo que no ha impedido que al menos uno alcanzara más resonancia pública que este, al estar vinculados otros actores como el Ayuntamiento, en el caso de la presentación pública en la plaza del barrio por el propio delegado de Salud, Seguridad y Emergencias del Ayuntamiento de Madrid del acuerdo del Pleno municipal de la proposición de Ahora Madrid de reconocer al distrito centro «libre de islamofobia» y que dotaba a la recién creada a la Unidad de Gestión de la Diversidad de la Policía Local de Madrid de competencias para recoger denuncias ciudadanas especialmente relacionadas con la islamofobia. Si bien existen otras cuatro comunidades musulmanas en activo en el barrio, fue Baitul Muqarram la que participaría activamente en el acto, celebrando después en su mezquita el citado iftar con la nutrida representación municipal, señal de una fluida interlocución pública.

Los otros dos actos, por su parte, fueron más minoritarios. La concentración contra los atentados estuvo organizada por la Baitul Muqarram y albergó a un centenar de fieles en medio del bullicio de una tarde de viernes; sin embargo, esta vez no contó con la participación pública, y sí con alguna que otra dificultad (Salguero, 2018: 132). La reciente conmemoración de los sucesos del 21 de febrero de 1952 en la Universidad Dacca fue promovida por la Asociación de Bangladesh en España, Madrid, al tratarse de un acto sin connotaciones religiosas y de claro reconocimiento de la diferencia, que está en el origen de la declaración por la UNESCO en 1999 del «Día Internacional de la Lengua Materna» en memoria del abatimiento a tiros por la policía pakistaní de varios estudiantes que estaban manifestándose por el reconocimiento de su lengua materna, el bengalí, en la Universidad de Dacca, por entonces Bengala Oriental y hoy capital de Bangladés, en un momento en el que las autoridades de Pakistán Oriental habían declarado el urdu como lengua oficial. En el acto se dieron cita, junto con algún que otro curioso, unas cincuenta personas convocadas por WhatsApp, en su mayoría bangladesíes, hombres y miembros de la asociación y, pese a su carácter secular, también fieles de Baitul Muqarram, algunos miembros destacados. En dos horas se depositaron coronas de flores, se leyeron varios comunicados en bengalí y precario castellano y se proyectó un vídeo en pantalla grande sobre esta conmemoración.

También se han organizado eventos seculares en espacios temporalmente públicos. Son los casos de las dos jornadas de puertas abiertas celebradas en 2017 y 2018, de la visita de la alcaldesa y el concejal del distrito a la mezquita en mayo de 2018 y de la participación de la comunidad en el programa «Conoce la diversidad religiosa de Madrid» de la Fundación La Merced Migraciones en noviembre de 2018. La visita en mayo de 2018 de Manuela Carmena y del concejal del distrito 
a la mezquita se realizaba con motivo de una reunión entre miembros de Valiente Bangla y de la mezquita, en la que se trataron temas como la sustitución de multas por trabajos comunitarios para los vendedores callejeros o el reforzamiento del servicio de voluntariado encargado de dar clases de español de apoyo a estudiantes bengalí parlantes. Esta reunión se producía en el aún caldeado ambiente tras los disturbios en Lavapiés dos meses antes por el fallecimiento de Mame Mbaye, un vecino de origen senegalés y «mantero» de profesión, que había sufrido una parada cardiaca cuando era perseguido por dos policías municipales por las calles del centro la tarde del 15 de marzo. Fruto de ello, la alcaldesa fue recibida por un grupo de manifestantes con pancartas en las que podía leerse «Poder racializado organizado»o «España será migrante, o no será». La resonancia mediática que tuvo esta recepción crítica fue mayor que la propia reunión, si bien ello también contribuiría a que fuese Baitul Muqarram, y no otra de las comunidades musulmanas del barrio, la que apareciese en los medios de comunicación como un fluido interlocutor con el Ayuntamiento; algo parecido a ser la única de estas que asistiera formalmente a la presentación pública de la campaña «Tacha el odio» en el palacio de Cibeles la mañana del viernes 8 de febrero de 2019, un gran evento municipal promovido por el Área de Gobierno de Salud, Seguridad y Emergencias del Ayuntamiento de Madrid y la Unidad de Gestión de la Diversidad de la Policía Municipal, con los que desde su creación el colectivo bengalí y musulmán ha mantenido diversos encuentros.

Las puertas abiertas han presentado cambios de la edición de 2017 (Salguero, 2018: 128-129) a la de 2018, empezando por la misma entidad convocante: si en 2017 fue la comunidad musulmana de Madrid Baitul Muqarram, este año convocaba el Centro Cultural Islámico Internacional. El plantel de actores invitados también contó con ciertos cambios. Los públicos contaron en 2018 con una representación municipal menor, incorporándose nuevas figuras, como el uniformado jefe de la Unidad de Gestión de la Diversidad, y repitiendo algunas otras, como la jefa de los Servicios Sociales del distrito, quien durante su intervención llamaría la atención a los organizadores por la nuevamente escasa presencia de mujeres en el acto y la vida pública en general. En lo confesional, el representante de la Comisión Islámica de España fue sustituido por otro del Centro Cultural Islámico de Madrid, quien ofreció una conferencia introductoria sobre los cinco pilares y algunas otras cuestiones básicas del islam, ante un foro de unas cien personas que había crecido notablemente en comparación con el año anterior y compuesto por fieles de la mezquita, representantes y trabajadores municipales, vecinos y vecinas, miembros de varias ONG y una decena de jóvenes solicitantes de protección internacional. 
Menor afluencia de público tendría dos semanas después la visita de un grupo de personas que acudía a la mezquita en el marco del programa «Conoce la diversidad religiosa de Madrid» promovido por la Fundación La Merced Migraciones en colaboración con varias entidades religiosas de Madrid, entre las que se encuentra Baitul Muqarram. La participación comunitaria así se desarrolla no solo en el ámbito institucional, sino también en el asociativo, alineándose con sus actores en cuestiones relacionadas con la convivencia y la solidaridad. Tras una pequeña espera a la finalización del tercer rezo del día, el 'asr, varios miembros de la comunidad charlaron con los asistentes, explicando esta vez sin «personalidades invitadas» nuevamente cuestiones básicas sobre el islam y otras más específicas, adhiriéndose a repertorios sociales generales, como el rechazo frontal a la violencia, o la manifestación expresa ante un foro presumiblemente progresista del distanciamiento doctrinal de Baitul Muqarram con el centro de la M-30, a quienes identifican como «más cerrados», mientras que la comunidad bangladesí quiere proyectar una imagen de comprensión del islam en el marco del respeto a la diversidad de creencias e ideologías, la convivencia intercultural y el enmarcado en los discursos de la modernidad.

La participación en el acto de reconocimiento del distrito libre de islamofobia y la organización de una concentración pública de rechazo a la violencia autodenominada yihadista son dos claras materializaciones en el espacio público de las demandas de inclusión en cuanto derecho de ciudadanía. En ambas se escenifica la asunción de Baitul Muqarram de valores compartidos por la sociedad en general; aluden su alineación con la sociedad que integran; y en esta ocasión no es necesario invisibilizar de algún modo la dimensión religiosa, pues el mensaje ulterior es que el islam promueve la paz. La tercera ocupación del espacio público responde más al interés por el reconocimiento de la diferencia, en este caso, en lo relativo a la lengua materna, el bengalí. Una diferenciación que en este caso es vital, teniendo en cuenta los hechos conmemorados y que precisamente otra de las comunidades musulmanas más relevantes del barrio sea la pakistaní, la cual cuenta en los soportales de la calle Sombrerete con el gran Centro Religioso de Pakistaníes en España y una asociación civil anexa de connacionales. Si bien no puede afirmarse que existe algún tipo de conflicto abierto entre ambas comunidades, las relaciones entre ellas son prácticamente inexistentes.

El énfasis en la diferenciación se emplea también en los espacios devenidos como temporalmente públicos. Uno clave es la visita de la alcaldesa y del concejal del distrito para celebrar una reunión formal sobre temas candentes, sociales y eminentemente seculares, que afectan de forma especial a la población bangladesí, como la precariedad del colectivo de vendedores callejeros o el generalizado 
escaso conocimiento de lengua española, también entre algunos escolares. Diferenciación también presente en la visita de la ONG, que espera encontrar en la comunidad religiosa un espacio aperturista e inclusivo y ante la cual se distancia expresamente de otros grupos de tradición más fundamentalista, a la vez que es una llamada a la inclusión adhiriéndose con una sociedad moderna y diversa. Las jornadas de puertas abiertas han perseguido las mismas pretensiones, en ellas se potencian elementos religiosos y étnicos en la búsqueda del reconocimiento social de sus especificidades religiosas y culturales, pero también son espacios de transparencia, temporalmente públicos, y por ende espacios para la inclusión. El espacio público penetra en el interior de la mezquita, y lo privado deviene en público. Aunque no siempre es una apuesta segura, y la transparencia también es a veces una improvisada salida a escena, en la que el evento puede ser evaluado por autoridades de distinto signo: municipales con el tirón de orejas municipal por la ausencia de mujeres, o asociativas ante la sutil ortodoxia de algunas de las aseveraciones del conferenciante de la M30 en las segundas jornadas.

\section{Conclusiones}

El colectivo musulmán bangladesí del barrio de Lavapiés sirve para ejemplificar los actuales procesos de institucionalización de las comunidades musulmanas más consolidadas, no tanto por su trayectoria vital si las comparamos con la de las primeras comunidades marroquíes inmigradas durante los noventa, sino por su significativo volumen de fieles en Lavapiés y su cada vez más intensa visibilización y participación en la vida pública del barrio y de la ciudad, en la cual también ha intervenido decisivamente el progresivo reconocimiento por parte del Ayuntamiento al colectivo islámico bangladesí, como ya ha quedado expuesto en anterior ocasión (Salguero, 2018: 135). La comunidad religiosa ha desempeñado así un relevante papel en la vida social del vecindario bangladesí, promoviendo desde los últimos años la creación de redes relacionales basadas en la pertenencia confesional y étnica, y la inclusión de la identidad cultural propia en el contexto de la acogida a través del contacto con las instituciones y con otros actores de la sociedad civil. En este orden, en el seno de la comunidad de fieles también se ha gestado una serie de repertorios seculares para el cambio social, frecuentemente relacionados con la comunidad inmigrada de creyentes.

Tanto el acceso y la visibilización en el espacio público como el ejercicio efectivo de la participación ciudadana en condiciones de igualdad con otros actores, confesionales y civiles, son comprendidos por Baitul Muqarram como derechos colectivos de ciudadanía, propios de una sociedad urbana y plural. Si el espacio público, en cuanto espacio para la alteridad, es donde se expresa e identifica so- 
cialmente la diversidad religiosa (Salguero, 2018: 135), la participación comunitaria junto con las instituciones y/o las asociaciones y ONG en asuntos locales de la vida social y política es donde ese reconocimiento en un principio parece materializarse en hechos reales, otorgándole mayor o menor capacidad de incidencia en el contexto del que forman parte. Sin embargo, el pleno ejercicio de estos derechos requiere en ocasiones para el colectivo inmigrado más condiciones que la titularidad misma. Para sortear estas dificultades añadidas, despliegan estrategias de visibilización y participación pública en distintos espacios: públicos, en las calles y plazas del barrio; temporalmente públicos, cuando la mezquita se abre al vecindario; y simbólicamente públicos, mediante la participación ciudadana traducida en interlocuciones públicas, en su inclusión en foros y plataformas ciudadanas o en la concesión de ayudas y programas sociales. En todos ellos, Baitul Muqarram se presenta como una comunidad religiosa alineada con la vida y política locales, adhiriéndose a los repertorios de la modernidad, por un lado, mediante la organización de eventos seculares públicos, en los que también se ponen en valor particularismos religiosos, étnicos y nacionales; $y$, por otro, a través de reiteradas muestras desestigmatizantes de transparencia ante el vecindario, la ciudadanía y las instituciones locales con motivo de la sospecha que sigue despertando el islam entre ciertos sectores de la sociedad española.

En los horizontes investigadores de este estudio de caso quedan pendientes de futuros análisis cuestiones como la permanencia del propio vecindario bangladesí en un barrio altamente turistificado, con cada vez menos oferta de vivienda residencial y, a su vez, más cara. ¿Desempeñará Baitul Muqarram algún papel en el proceso de gentrificación que está azotando al barrio, y también a sus precarios fieles? ¿Tendrán cabida en la marca del barrio más cool del mundo un gran centro cultural islámico y la celebración de grandes rituales religiosos? Otra cuestión que también presenta nuevos interrogantes es la referente a la capacidad de agencia e incidencia que tenga la comunidad sobre la vida pública en un posible contexto de cambio social y político tras las inminentes elecciones generales y locales, marcado por el endurecimiento de las condiciones de vida de las personas extranjeras en España y por formas menos igualitarias de gestión pública del pluralismo religioso, en el caso de una hipotética victoria del eje conservador. ¿Seguirá ostentando Baitul Muqarram esta representatividad en diversos ámbitos públicos o quedará relegada nuevamente a mera espectadora? ¿Verá satisfechas sus demandas de derechos de ciudadanía o tendrá que centrarse otra vez en las necesidades básicas, materiales y espirituales, de sus fieles? Las respuestas están en futuras investigaciones. 


\section{Bibliografía}

Algora, María Dolores (2011). «Hacia un Madrid cosmopolita. La nueva presencia árabe en Madrid». En Daniel Gil Flores (ed.) (2006). De Maŷrit a Madrid. Madrid y los árabes, del siglo IX al siglo XXI (pp. 216-221). Madrid: Casa Árabe.

Alguacil, Julio (2008). «Espacio público y espacio político. La ciudad como el lugar para las estrategias de participación». Revista Polis, 7(20): 199-223.

Alonso, Marta et alii (2010). «Rituals islàmics en diáspora: Les comunitats musulmanes a Catalunya». Revista d'etnologia de Catalunya, 36: 171-176.

Ambrosini, Mauricio (2008). «Participación religiosa e integración de los inmigrantes. Una reflexión entre América y Europa, entre historia y actualidad». Migraciones, 23: 11-44.

Bell, Catherine (1992). Ritual theory, ritual practice. New York: Oxford University Press.

Berger, Peter (1967). The Sacred Canopy: Elements of a Sociological Theory of Religion. Garden City, NY: Doubleday.

Blázquez-Rodríguez, Maribel; Cornejo, Mónica y Pichardo, J. Ignacio (2018). «La disputa del género en el estado español desde el análisis del activismo católico». Ex aquo, 37: 47-61. doi: 10.22355/exaequo.2018.37.04.

Bromberger, Charles (1995). «Football as world-view and as ritual». French Cultural Studies, 6(18): 293-311.

Самасно, Javier (2013). Resumen de las reuniones con los grupos de población bangladesí de Lavapiés. Madrid: Centro Social Comunitario Casino de la Reina del Ayuntamiento de Madrid.

Carrión, Fernando (2007). «Espacio público: punto de partida para la alteridad». En Olga Segovia (ed.) (2007). Espacios públicos y construcción social. Hacia un ejercicio de ciudadanía (pp. 79-97). Providencia: Ediciones Sur.

Eade, John y Garbin, David (2002). "Changing Narratives of Violence, Struggle and Resistance Bangladeshis and the Competition for Resources in the Global City». Oxford Development Studies, 30(2): 137-149. doi: $10.1080 / 13600810220138258$.

Falk Moore, Sally y Myerhoff, Barbara G. (eds.) (1977). Secular Ritual: A Working Definition of Ritual. Atlantic Highlands, NY: Humanities.

Fundación Pluralismo y Convivencia (2018). Guía de apoyo para la gestión de las festividades, celebraciones y conmemoraciones de las confesiones religiosas minoritarias en el espacio público. Madrid: Observatorio del Pluralismo Religioso en España. 
García-García, Sergio (2014). «\#Policíasenacción. El Plan de Seguridad de Lavapiés». Contested_Cities. Working paper series, 14006. Disponible en $<$ http://contested-cities.net/workingpapers/2014/policiasenaccion-elplan-de-seguridad-de-lavapies/> [consulta: 2 de marzo de 2019].

Gómez, Mayte (2012). «El barrio de Lavapiés, laboratorio de interculturalidad». Dissidences. Hispanic Journal of Theory and Criticism, 1, 2(12): 1-42.

Gramsci, Antonio (1971). Selections from the Prison Notebooks. London: New Left Books.

Hudson, Wayne (2003). «Religious Citizenship». Australian Journal of Politics and History, 49(3): 425-429.

Kepel, Gilles (1995). La revancha de Dios. Cristianos, judios y musulmanes a la reconquista del mundo. Madrid: Anaya; Mario Muchnik.

Leach, Edmund (1976). Culture and Communication: The Logic by Which Symbols are Connected. Cambridge: Cambridge University Press.

Lefebvre, Henri (2013). La producción del espacio. Madrid: Capitán Swing.

Luckmann, Thomas (1967). The invisible religion: The problem of religion in modern society. New York: Macmillan.

Mijares, Laura y Lems, Johanna (2018). «Luchando contra la subalternidad: las reivindicaciones de la población musulmana en Madrid». Revista de Estudios Internacionales Mediterráneos, 24: 109-128. doi: 10.15366/reim2018.24.007

Moreras, Jordi (1999). Musulmanes en Barcelona. Espacios y dinámicas comunitarias. Barcelona: Fundació CIDOB.

Observatorio Andalusí (2018). Estudio demográfico de la población musulmana. Explotación estadística del censo de ciudadanos musulmanes en España referido a fecha 31/12/2017. Madrid: UCIDE.

Pérez, Vicente (2009). Intervención y rehabilitación, 1998-2008. Madrid: Ayuntamiento de Madrid y Federación Regional de Asociaciones de Vecinos.

Pfadenhauer, Michaela (2010). «The eventization of faith as a marketing strategy: World Youth Day as an innovative response of the Catholic Church to pluralization». International Journal of Nonprofit and Voluntary Sector Marketing, 15(4): 382-394.

Planet, Ana I. (2018). «Islam in Spain: From Historical Question to Social Debate». En Aana I. Planet (ed.) (2018). Observing islam in Spain. Contemporary Politics and Social Dynamics. Leiden, Brill: 1-22. doi: $10.1163 / 9789004364998$.

Salguero, Óscar (2010): «Necesidades de las comunidades religiosas en Andalucía». En Rafael Briones (dir.) (2010). ¿Y tú (de) quién eres? Minorías religiosas en Andalucía (pp. 481-492). Barcelona: Icaria. 
Salguero, Óscar (2014). Espacio público y privado en el contexto del pluralismo religioso: minorías religiosas en Granada y su área metropolitana. Granada: Universidad de Granada.

Salguero, Óscar (2018). «Baitul Muqarram: el islam en el espacio público del barrio de Lavapiés». Revista de Estudios Internacionales Mediterráneos (REIM), 25: 111-138. doi: 10.15366/reim2018.25.

Sequera, Jorge (2014). "Gentrificación en el Centro Histórico de Madrid: el caso de Lavapiés». En Michael Janoschka y Ricardo Hidalgo (eds.) (2014). La Ciudad Neoliberal. Gentrificación y exclusión en Santiago de Chile, Buenos Aires, Ciudad de México y Madrid (pp. 233-255). Santiago de Chile: Instituto de Geografía, Pontificia Universidad Católica de Chile / Departamento de Ciencia Política y Relaciones Internacionales y Universidad Autónoma de Madrid.

Thiebaut, Carlos (1998). Vindicación del ciudadano. Barcelona: Paidós.

Vaggione, Juan M. (2005). «Reactive Politicization and Religious Dissidence. The Political Mutations of the Religious in Social Theory and Practice». Social Theory and Practice, 31(2): 233-255. doi: 10.5840/soctheorpract 200531210. 